\title{
CRENÇAS DE PROFESSORES E ALUNOS: o uso de mídia social como prática de língua inglesa
}

\author{
TEACHERS' AND STUDENTS' BELIEFS: the use of social media as an english \\ language practice
}

Talita Costa Pereira ${ }^{16}$

\begin{abstract}
RESUMO: O estudo de crenças acerca do processo ensino-aprendizagem de Língua Estrangeira sustentou este artigo, o qual objetivou interpretar os possíveis benefícios à aprendizagem de Língua Inglesa por meio do uso de mídia social como prática de aprendizado de línguas, bem como as crenças de professores e alunos de uma escola de línguas, no que se refere a esta prática. Para isso, utilizamos questionários semiestruturados com perguntas abertas para o levantamento de dados dos entrevistados, buscando evidenciar as mídias sociais como uma proposta de prática da Língua Inglesa diariamente. Partindo do pressuposto que o professor usa de mídias sociais não somente para comunicados, mas também para maior interação da turma, usando, no cotidiano, a língua a ser aprendida, em outros momentos que não a sala de aula. Tendo como aporte teórico Barcelos (2001) e Barcelos e Abrahão (2006) sobre crenças e o ensino de línguas, comparamos as crenças dos entrevistados com suas práticas através dos grupos das turmas nas mídias socias Whatsapp e Facebook, e por meio destes constatamos o esforço dos professores ao incentivar seus alunos a praticarem língua inglesa utilizando das ferramentas tecnológicas para tal prática, igualmente o reconhecimento dos alunos quanto às ferramentas colaborarem com o desempenho linguístico.
\end{abstract}

PALAVRAS-CHAVE: Crença. Mídias Sociais. Prática de língua.

ABSTRACT: The study of beliefs concerning the teaching-learning process of Foreign Language supported this article, which aimed to expound the possible benefits to English Language learning through the use of social media as a practice of language learning, as well as the teachers' and students' beliefs from a language school, regarding this practice. For this purpose, we used semi-structured questionnaires with open questions to collect data from the interviewees, seeking to point social media as a proposal of English language practice daily. Based on the assumption that teachers use social media not only for communication, but also for greater interaction among students, using, in everyday life, the language to be learned, at times beyond the classroom. Based on the theoretical contribution of Barcelos (2001) and Barcelos and Abrahão (2006) on beliefs and language teaching, we made a comparison between the interviewees' beliefs and their practices through the groups in social medias as Whatsapp and Facebook, and hereby we found out that teachers encouraged their students to practice English using the technological tools for this practice, besides students' recognition of how the tools contribute to their linguistic performance.

KEYWORDS: Belief. Social Medias. Language practice.

\section{Introdução}

Atualmente no mundo digital, é possível encontrar diversas ferramentas auxiliadoras do aprendizado de Língua Inglesa, como por exemplo: o canal no YouTube chamado "Englishanyone", uma página no Facebook chamada "Inglês na ponta da língua", um perfil no Instagram chamado "Inglês sem neura", um grupo de conversação no aplicativo Whatsapp chamado "clube do inglês", entre outros numerosos que possibilitam o acesso a língua inglesa há quem interesse.

As mídias sociais mencionadas anteriormente têm sido utilizadas há algum tempo pela presente autora deste projeto, como instrumento de informação, de prática contínua da língua e de desenvolvimento profissional, já que constantemente utilizava-se dicas de gramática e vocabulários para ensinar seus alunos. Práticas estas que levantaram alguns questionamentos: Será que meu aluno tem conhecimento de redes como estas? Se sim, ele participa delas para

\footnotetext{
${ }^{16}$ Mestranda pela Universidade Federal do Amazonas - UFAM. E-mail: talita_mps@hotmail.com
} 
complementar seu aprendizado? Se não conhece, ele procura conhecer? De que forma, eu como professora posso facilitar essa prática?

Essas questões são sempre necessárias ao desenvolvimento profissional, haja vista que "as mudanças no mundo globalizado indicam que a função de professor requer uma grande quantidade de ideias, de habilidade nos procedimentos, no modo de lidar com os alunos, nas estratégias de ensinar, entre outros" (RODRIGUES, 2012, p. 43). Isso significa que os grandes artifícios utilizados nas estratégias de ensino surgem, em sua maioria, a partir de questionamentos, principalmente se auto indicativos. Por isso, em meio a estas reflexões surgiram as questões problemáticas desta pesquisa: O professor de língua inglesa acredita no uso das mídias sociais como auxílio na prática do inglês? E o aluno acredita no seu desenvolvimento com ajuda dessas mídias? De que forma o uso dessas tecnologias pode ser eficaz ao aprendizado de língua inglesa?

Acreditamos que com a interação dos alunos através das novas mídias sociais, os mesmos tenham mais tempo para praticar o que já foi aprendido em sala de aula, e assim desenvolver melhor seu desempenho nas competências linguísticas: compreensão e produção oral, compreensão e produção escrita. Em vista disso, buscamos investigar as prerrogativas possíveis à aprendizagem de Língua Inglesa por meio do uso de mídia social como prática de aprendizado de línguas, tal como as crenças de professores de inglês e alunos de um curso de idiomas referente ao uso dessas mídias como prática da língua alvo. Para tanto, propomos nos tópicos seguintes discorrer sobre as crenças e inovações no ensino de línguas, a perspectiva dos professores e dos alunos entrevistados, e a comparação de suas crenças com as práticas em questão.

\section{Ensino de línguas: crenças e inovações}

Estamos vivendo em uma época de grandes novidades, em que, por meio de ferramentas digitais, podemos ter acesso a tudo e a todos mais facilmente. É a "Geração da Tecnologia" acompanhada da internet que se desenvolveu como a mídia mais promissora, através da qual as pessoas passaram a se comunicar com mais frequência e a compartilhar informações e experiências de forma instantânea. Embora muito utilizada com intuito de lazer, a internet passou a desempenhar funções nas vendas, trabalho, universidades, empresas e até na educação, já que "na internet, encontramos vários tipos de aplicações educacionais: de divulgação, de pesquisa, de apoio ao ensino e de comunicação" (MORAN, 1997, p. 1).

A tecnologia tem influenciado muito na educação por ser algo que atinge a sociedade. Ainda assim, esse novo mecanismo divide opiniões, sendo muitas contrárias ao uso das mídias sociais. Porém não se pode controlar um instrumento que ganhou tamanha força nos últimos anos. Logo, se torna significativo entender de que forma a tecnologia e a educação podem ser aliadas, tal como a importância dessa aliança. Cristiane Barbosa explicita que

devido ao grande avanço tecnológico e as mudanças no sistema educacional, a relação Educação e Tecnologia vem se estreitando de maneira relevante na atual sociedade. Diante dessa realidade, é importante entender que o processo educativo ocorre em vários lugares e de várias maneiras. O espaço escolar não é o único e exclusivo local no processo de construção do conhecimento. (BARBOSA, 2010, p. 4)

Além disso, podemos observar que com o uso das mídias sociais para praticar a língua inglesa, alunos e professores conseguem alcançar as três categorias básicas do objetivo educacional que Stern (1987) se refere, sendo elas: 
Aprendizagem conceitual e verbal - inclui informações, conhecimento, ideias, conceitos e sistema de pensamento; Habilidades - aprendizado referente a aquisição do processo sensório-motor, [...] Aprendizagem afetiva e social - refere-se à aquisição de condutas emocionais e expressões, interesses, atitudes sociais e valores (STERN, 1987, p. 310, tradução nossa). ${ }^{17}$

Deste modo, consideramos que as mídias sociais, se utilizadas de maneira ideal, contribui com os três componentes citados acima. Primeiro, que o constante acesso a conteúdo extras de vocabulários, expressões e de gramática, compõe a aprendizagem conceitual e verbal. Esta, podendo ser realizada pelo próprio estudante através de redes sociais, blogs, jogos, etc. sem que para isso haja a dependência a um professor. Segundo as habilidades sensório-motores podem ser praticadas de forma mais completas através de aplicativos de bate-papo, já que por meio de áudios, vídeos e textos é possível desenvolver as quatro habilidades linguísticas: Speaking, Listening, Reading and Writing. Esta última podendo ser motivada pelo professor com homeworks virtuais, por exemplo, ou por diálogos naturais. Por fim, essa inovação possibilitou a comunicação de professores e alunos entre si e uns com os outros facilitando a interação de forma rápida, flexível e com pouco custo. Essa interação contínua dos alunos desenvolve a aprendizagem afetiva e social.

O que entendemos por aprendizagem hoje em dia, principalmente em se tratando de aquisição de linguagem, é muito mais abrangente do que a relação aluno-professor, podendo ocorrer também de forma independente ou através da interação natural no dia a dia, como afirma Stern (1983, p. 20, tradução nossa) "algumas das formas de aprendizagem são estimuladas pelo ensino, mas muitas delas podem ser independentes de qualquer ensinamento"". Marinović (2012) sustenta o mesmo pensamento quando declara que "a aquisição ou assimilação de uma língua está mais ligada ao convívio humano e às situações naturais". Isso significa que, mais do que o processo formal e mecanizado de uma sala de aula, a aprendizagem dos alunos também provém do desenvolvimento de competências linguísticas por meio de experiências alheias.

Em vista disso, alguns profissionais da educação têm se motivado a dispor dessas ferramentas como contribuintes ao processo ensino-aprendizagem. Barbosa (2010, p. 7) afirma ainda que "[...] é necessário que os professores estabeleçam pontes entre o conhecimento formal e a aprendizagem informal que ocorre fora da sala de aula". Nas redes sociais é possível encontrar, por exemplo: vídeo-aulas de professores que respondem as dúvidas de alunos; grupos de escola e universidades em que se compartilham arquivos do conteúdo ensinado; debates em redes sociais sobre assuntos diversos, formadores de opinião, que surgiam apenas em sala de aula; redes sociais que auxiliam a comunicação com pessoas de todo o mundo, seja em inglês, espanhol ou qualquer outra língua de interesse.

$\mathrm{O}$ ensino de línguas pode ser definido como qualquer atividade que atribua conhecimento de línguas a alguém, não somente por meio das aulas convencionais e dos livros, mas também da rádio, da televisão, do self-study, do computador. Neste caso, entendemos então que as mídias sociais ligadas a internet como websites, e-mail, aplicativos e etc. podem ser ferramentas importantes para o processo ensino-aprendizagem de línguas quando Stern (1993, p. 21, tradução nossa) reconhece que "usando a linguagem em situações

\footnotetext{
${ }^{17}$ Conceptual and verbal learning includes information, knowledge, ideas, concepts, and systems of thought. Skill learning refers to the acquisition of sensorimotor processes, [...] Affective and social learning refers to the acquisition of emotional conduct and expression, interests, social attitudes, and values.

${ }^{18}$ Some learning is stimulated by teaching, but much of it may be independent of any teaching.
} 
não planejadas, 'ensina' línguas de forma mais eficaz do que a instrução formal de sala de aula"19.

Mesmo com diferentes possibilidades de aplicação na educação, o uso da tecnologia ainda divide opiniões: algumas pessoas acreditam que seu uso é benéfico e outras não. Contudo, não podemos julgar as crenças, principalmente quando se trata de ensinoaprendizagem.

Em seus estudos sobre crenças, Barcelos afirma:

Entendo crenças, de maneira semelhante a Dewey (1993), como uma forma de pensamento, construções da realidade, maneiras de ver e perceber o mundo e seus fenômenos, co-construídas em nossas experiências resultantes de um processo interativo de interpretação e (re) significação, como tal, crenças são sociais (mas também individuais), dinâmicas, contextuais e paradoxais. (BARCELOS, 2006, p.18)

Barcelos define crenças como: sociais, por construírem e representarem uma realidade social; dinâmicas, por se modificarem mediante a época em que se vive; contextuais, por se desenvolverem em conformidade com os ambientes, com as experiências e interações dos indivíduos e entre si; e paradoxais, por servirem como instrumento ou como obstáculo para o ensino-aprendizagem de línguas, sendo assim sociais e individuais ao mesmo tempo.

Logo, para falar de crenças no âmbito do processo ensino-aprendizagem, devemos considerar o contexto social, sociocultural dos alunos e dos professores, bem como suas experiências, ou seja, "as crenças podem ser pessoais ou coletivas, intuitivas e na maioria das vezes são implícitas" (SILVA, 2007, p. 247).

Por isso, é importante citar que o professor possui o papel de "[...] educador, orientador, inovador, fascinador, facilitador, promotor de autonomia, ponte cultura[...]" (PERINA, 2003, p. 94), cuja tarefa é instruir, motivar e orientar o uso dessa tecnologia e sua importância no processo de aprendizagem, não podendo impor tal instrumento, mas sim sugerir e incentivar, pois, cada indivíduo conhece a própria condição, os meios facilitadores e dispõe de crenças pessoais acerca do processo de aquisição do conhecimento. Isso quer dizer que, se o aluno ou professor acredita na tecnologia, na internet, nas mídias sociais, etc. como ferramenta facilitadora da obtenção de conhecimento, e neste sentido, se faz o uso da tecnologia, então o objetivo foi alcançado, caso contrário, será apenas um meio de diversão e lazer, visto que segundo Moran (1997, p. 8) "o poder de interação não está fundamentalmente nas tecnologias, mas nas nossas mentes". Deste modo, entende-se que as mídias sociais não transformam o processo ensino-aprendizagem se não houver crença associada à prática.

Em vista disso, diferentemente dos primeiros estudos que denominavam crenças como estruturas mentais fixas justificadas pelas ações, sendo discriminadas como certas e erradas, este trabalho propôs uma pesquisa em relação às crenças dos professores e dos alunos a respeito das mídias sociais como instrumento na prática da língua inglesa, em concordância com suas experiências, realidades e interações, visando a relação entre suas crenças e suas ações. O intuito não foi de classificá-las, mas sim de interpretá-las baseando-se nos diversos contextos envolvidos.

\section{Metodologia}

Para a realização deste projeto, utilizamos das abordagens metacognitivas e contextuais, ou seja, fizemos entrevistas por intermédio de questionários semiestruturados contendo perguntas abertas, além da observação quanto ao uso das mídias sociais no dia a dia

${ }^{19}$ Using the language in unplanned situations, 'teach' languages more effectively than formal classroom instruction. 
para fazer a comparação das respostas com as práticas. A coleta de dados ocorreu por meio das respostas de 10 alunos do nível básico, na faixa etária entre 18 e 30 anos, de duas turmas diferentes, com seus respectivos professores de Língua Inglesa de um curso livre de idiomas cuja metodologia é Abordagem Comunicativa, localizada na cidade de Manaus. Essas turmas se propuseram a responder ao questionário, além de incluírem a pesquisadora nos seus grupos fechados nas mídias sociais Whatsapp e Facebook para observação das práticas. Pretendemos comparar e interpretar as crenças de ambas as partes voltadas para o uso dessas mídias como exercício da Língua Inglesa no dia a dia, além de relatar os pontos positivos e/ou negativos de acordo com suas respectivas respostas sobre o uso do método aqui abordado.

\section{Análise dos resultados}

Acreditamos que cada professor e aluno possui suas próprias crenças de aprendizagem de línguas e que levam consigo para as aulas, bem como para as práticas, podendo haver mudanças ou se manterem vivas durante o processo de ensino. Por isso nos apoiamos em Silva (2005) quando afirma que

\footnotetext{
As crenças na teoria de ensino e aprendizagem de línguas são essas ideias que tanto alunos, professores e terceiros têm a respeito dos processos de ensino/aprendizagem de línguas e que se (re)constroem neles mediante as suas próprias experiências de vida e que se mantêm por um certo período de tempo. (SILVA, 2005, p. 77)
}

Sendo assim, interpretamos as crenças de alunos e professores quanto ao uso de mídias sociais como ferramenta auxiliadora do ensino aprendizado de língua inglesa, relacionando suas perspectivas às práticas, obtendo os seguintes resultados.

\section{1 Perspectiva do professor}

Conforme citado anteriormente, existem outros meios, além da escola, que atuam como agentes educadores, por exemplo, as tecnologias. Nesse caso, essas tecnologias são voltadas as mídias sociais, estas seriam o Facebook, o Whatsapp, o YouTube etc. Os professores entrevistados afirmaram fazer uso das mídias sociais para interação da turma e para praticar o inglês fora de sala de aula. Ambos disseram acreditar que essa tecnologia possa auxiliar no processo de ensino-aprendizagem, quando foi lhes perguntado:

$\mathrm{P}^{20}$ : Você acredita que as mídias sociais como meio de interação da turma contribuem para a prática de Língua Inglesa fora de sala de aula? Justifique-se.

$\mathrm{PE}^{21}$ : Acredito que sim, pois o maior obstáculo do aluno é saber que deve praticar fora de sala e não ter com quem praticar.

PE2 ${ }^{22}$ : Sim. É uma situação real (o uso de uma mídia social), e isso os aproxima da lingua.

É perceptível que ambos os professores entrevistados acreditam na importância das mídias sociais em benefício do processo ensino-aprendizagem de língua inglesa, uma vez que elas funcionam como auxílio ao aluno consciente que precisa praticar o Inglês fora de sala, porém não sabe como, além de ser uma forma diferente de obter conteúdos extras da língua.

Vale ressaltar que a turma do Professor Entrevistado 1 (PE1) possui um grupo no aplicativo denominado Whatsapp e um grupo na rede social Facebook, os quais se faz uso há

\footnotetext{
${ }^{20}$ Pesquisador

${ }^{21}$ Professor Entrevistado 1

${ }^{22}$ Professor Entrevistado 2
} 
dois semestres - tempo que o professor vem trabalhando com a turma. Enquanto a turma do Professor Entrevistado 2 (PE2) possui um grupo no aplicativo Whatsapp, ambos com 3 meses de vivência.

É importante, porém, que haja uma postura adequada dos professores quanto ao uso desses meios para que objetivo seja alcançado. Cristiane Barbosa afirma: "Para que esses recursos sejam utilizados corretamente, é preciso que os professores estejam preparados [...] pois é necessário que o educador saiba favorecer a aprendizagem mediada pela tecnologia" (BARBOSA, 2010, p. 2). Por este motivo, perguntou-se:

P: De que forma você influencia a turma a fazer uso dessas tecnologias como prática de Língua Inglesa (áudio, vídeo, textos)?

PE1: Digo a eles sempre que a exposição (à língua) é importante para aproximar o uso da língua ao cotidiano deles.

PE2: Sempre envio links de vídeos, explicações, além de enviar exercícios.

É perceptível que PE1 e PE2 são grandes incentivadores e influenciadores devido suas crenças, no entanto, "para um desempenho profissional satisfatório, o educador necessita acompanhar as mudanças que estão ocorrendo e a flexibilidade para inovar e se transformar constantemente. Nada disso será feito se não houver reflexão" (RODRIGUES, 2012, p. 44), de forma que os sujeitos possam manter suas crenças vivas, ou alterá-las, após passar por experiências que construam os sentidos delas. Tendo em vista disso, questionou-se aos professores-entrevistados:

P: Você já notou alguma diferença no rendimento dos alunos devido ao uso dessas tecnologias? Cite exemplos.

PE1: Sim, por exemplo, um aluno disse que passou a entender letras de músicas ao ouvir a elas enquanto le a letra. Disse ter percebido que muitas palavras ele conhecia e o mesmo passou a fazer isso e a trocar essas músicas com a namorada pelo Facebook.

PE2: Em determinados alunos sim. Eles passaram a aumentar a frequência em sala e houve melhora dos demais exercícios.

As crenças dos professores no método utilizado por eles a pouco tempo se confirmam não apenas pela teoria, mas pela percepção quanto ao avanço de seus alunos que confirmam na prática a eficiência desse novo modo de praticar a língua. E para que essa nova metodologia possa ser compartilhada, os professores foram solicitados:

P: Escreva suas considerações com relação ao uso das mídias sociais como prática da Lingua Inglesa.

PE1: Acho que toda forma de exposição é muito válida e as mídias são de uso constante dos alunos o que facilita o acesso à Língua Inglesa.

PE2: É um ótimo recurso se utilizado com frequência e com propósito final.

É evidente então que os professores entrevistados acreditam fielmente na prática de Línguas através de mídias sociais e tentam passar a seus alunos que tirem o máximo proveito desses meios facilitadores do ensino, seja em grupo comum com a turma ou sozinhos em suas redes sociais particulares ou com outros amigos. O importante para eles é motivarem a sempre manterem a prática da língua em questão, não importando a tecnologia que esteja em vigor.

\subsection{Crenças dos alunos}

Os alunos entrevistados mostram que seus interesses pelas mídias sociais, como prática de Língua Inglesa, tiveram início com o grupo da turma atual em que estudam no curso de línguas, ou seja, suas crenças surgiram graças a essa nova prática, sendo considerado algo comum, posto que "o estudo de Alien (1996) mostra, primeiro, que as crenças estão inter- 
relacionadas com as experiências dos alunos e segundo, que as crenças não são tão estáveis como se costuma pensar" (BARCELOS, 2001, p. 82). Uns admitem o uso apenas aos finais de semana enquanto outros usam constantemente, porém, todos os entrevistados afirmam interagirem com a turma nos grupos do Facebook e/ou Whatsapp.

Quanto aos alunos entrevistados, os intitulamos com os respectivos nomes fictícios de: Alves, Bezerra, Klésia, Gomes, Marques, Santos, Pereira, Silva, Araújo e Souza, com o intuito de relatar suas respostas sem que pudessem ser identificados.

Conforme mencionado anteriormente, as crenças podem se formar mediante experiências e contextos. Diante disto, indagou-se aos alunos:

P: Na sua opinião, qual a importância da interação da turma na prática da Língua Inglesa através dessa tecnologia?

Alves: Muito importante, para interagir e perder também o medo de se expor ao "ridiculo" por não dominar a língua.

Bezerra: Essa interação é importante porque é uma oportunidade a mais de praticar o conteúdo das aulas.

Klésia: Extremamente importante, pois auxilia no vocabulário, desenvoltura, familiaridade com a língua.

Marques: $O$ uso da Lingua Inglesa durante interação nesses meios, facilita o acesso e ao mesmo tempo faz com que os alunos percam o medo de se comunicar usando outro idioma.

Gomes: A importância é compartilhar conhecimento, o que aprendeu em sala de aula,o que sabem, o que querem saber e o que precisam saber, dando ao participante do grupo mais segurança na escrita e na pronúncia do idioma.

Santos: Praticar o que aprendemos em sala de aula.

Pereira: É uma forma de interagir. Colocar em prática o que é ensinado em sala de aula.

Silva: Para agregar conhecimento

Araújo: Muito importante, ainda mais nas dúvidas.

Souza: Possibilita a prática da língua fora de sala de aula.

Com o experimento da interação da turma em Inglês através das mídias sociais, os alunos passaram a notar relevância na prática. Ademais, os benefícios que esse exercício pode acarretar ao estudo de Inglês, quando questionados:

P: Que beneficios você obteve (ou pudesse obter) com a prática da Língua Inglesa através das tecnologias?

Marques: Por usar a internet e as novas tecnologias estarem acessiveis através de dispositivos móveis, os alunos podem pesquisar e até indicar novos meios de praticar o idioma. Inglesa.

Klésia: Maior conhecimento de vocabulário, pronúncia, cultura e costumes da Língua

Bezerra: Aprendi palavras novas e memorizei como compor sentenças e perguntas no idioma que estou estudando.

Alves: Interação com outras culturas, trocas de informação, participação de grupos e etc.

Gomes: Um grupo de estudo da turma para comunicação da língua inglesa que tem como base a comunicação simples do cotidiano do idioma e o mais importante é saber que existe alguém (administradora-professora) com o interesse de querer ensinar, captar $e$ inspirar os demais em buscar mais e mais conhecimento para expandir o vocabulário.

Santos: aprendizado no dia-a-dia.

Pereira: a tecnologia ajuda muito, pois a interação ocorre mais rápida.

Silva: conhecimentos 
Araújo: vários. Tenho aprendido e tirado dúvidas através de vídeos.

Souza: eu faço pesquisas para escrever corretamente durante um diálogo e acabo descobrindo palavras novas.

Outro benefício que alguns alunos puderam ter com essa experiência, talvez não tenha sido notada, foi a motivação de perdurar esse hábito com a turma ou com outros grupos, para que o uso do Inglês seja constante, uma vez que na maioria dos casos, não se tem em sua rotina. Isso fica claro nas respostas da última pergunta do questionário:

P: Escreva sobre sua experiência com relação ao uso dessas tecnologias com a turma ou com outros falantes da Língua Inglesa. Se nunca teve experiências com outros falantes que não a turma, você pretende obter essa interação? Justifique-se.

Alves: Até o momento foi um tanto dramático, por não dominar a língua. Mas não desisto, pois, a frequência é muito grande, principalmente no ambiente de trabalho.

Bezerra: Não converso com frequência com outras pessoas através das mídias sociais, mas nas vezes que conversei gostei bastante. É um desafio e me estimula a aprender sentenças novas e como formular frases complexas.

Klésia: Aqui na turma não utilizo muito, mas tenho amigos que utilizam o Whatsapp e é excelente para exercitar a língua e fixar o aprendizado. Pretendo buscar mais essa interação.

Marques: Apesar de ainda não ter boa prática na conversação, a leitura e escrita tem melhorado bastante com o uso das tecnologias. Consigo ler sites estrangeiros, comentar em "fanpages" internacionais e ouvir música com melhor entendimento das letras.

Santos: a experiência é que aprendemos através de diálogos com toda a turma.

Pereira: minha experiência com a turma é boa pois nós podemos aprender juntos, compartilhando informações novas que vem a somar com aprendizado. Porém nunca tive experiência externas.

Silva: sim, para obter conhecimento.

Araújo: Bom, em relação a turma tem sido proveitosa, mas ainda não tive contato com outros grupos.

Souza: Pretendo ter interação com outros falantes para adquirir experiência na fala.

É perceptível que os alunos se mantêm inspirados e encorajados em continuar essas experiências ou buscar novos conhecimentos de outras formas. Além de melhorar nas habilidades, os alunos mostraram-se mais seguros para praticar a língua dessa forma e também de outros modos, sempre inserindo em suas atividades o Inglês, não importa qual seja esse exercício.

\subsection{Comparando prática e crença}

Buscamos investigar se alunos e professores possuem crenças acerca do uso de ferramentas sociais como forma de praticar a língua inglesa fora de sala de aula e quais seriam os possíveis benefícios. Nos parece ser claro que os professores entrevistados acreditam na eficiência das mídias sociais para prática de Língua Inglesa, e que devem motivar seus alunos a usá-las. E para certificar essa informação, fizemos observações nos grupos do WhatsApp e Facebook das turmas, que duraram cerca de uma semana cada, tempo que estimamos ser suficiente para comparação de dados, cujos resultados seguem abaixo.

A afirmação da PE2 se confirmou durante as observações, em que ficou clara a utilização das mídias, para atividades extras que possibilitasse aos alunos praticarem o Inglês, enviando conteúdos extras de vocabulário, áudios em inglês com saudações e textos tirando dúvidas. Isso se refletiu na prática dos alunos, pois eles próprios, muitas 
das vezes, tiveram a iniciativa do diálogo entre si, usando termos provavelmente aprendidos em sala de aula.

Quanto as observações dos grupos do PE1, notou-se que o grupo do WhatsApp foi utilizado com função maior de comunicados e avisos sobre o curso de Inglês, utilizando a língua alvo de aprendizado. Já no grupo da rede social Facebook, foi constantemente utilizado para envio de mensagens em inglês, motivacionais, esclarecimento de dúvidas e etc.

Essas práticas diárias certamente fazem a diferença no processo de ensino/aprendizado de línguas dos alunos, visto que, sabemos da importância do convívio entre o aluno e a língua que se aprende.

\section{Considerações finais}

O estudo aqui realizado teve como objetivo identificar as crenças dos professores e dos alunos de Inglês, submetidos à esta pesquisa, acerca da prática da língua alvo, por meio das mídias sociais, estas bastante presentes no cotidiano dos cidadãos, em virtude do acelerado avanço tecnológico que temos experimentado nos últimos anos. Foi estimulado o uso das mídias sociais pelo professor como atividade extracurricular, para auxiliar o aluno a manter a rotina de uso do Inglês. Os objetivos e os procedimentos metodológicos aplicados nesta pesquisa, nos possibilitaram reflexões a respeito da função das crenças dos professores e dos alunos no processo ensino-aprendizagem de línguas, no nosso caso, acerca da língua inglesa.

Conforme analisado por intermédio deste projeto, há uma relação interativa, em que as crenças e as ações dos professores e dos alunos, indivíduos desta pesquisa, se influenciam mutuamente.

Ao colocarem em prática esta possibilidade, a de se trabalhar por meio das mídias sociais, os professores notaram o esforço e aprimoramento das competências linguísticas de seus alunos, e os alunos por sua vez, reconheceram resultados positivos em si mesmos ao revelarem que através das práticas dos grupos enriqueceram seu vocabulário, conseguiram construir sentenças em inglês e puderam interagir mais utilizando a língua inglesa para além da sala de aula. Por conseguinte, professores e alunos passaram a reforçar as crenças, em virtude de bons resultados alcançados.

Ademais essa aplicação constante da língua nas mídias sociais, já utilizadas como lazer, complementa o ensino da escola de idiomas cuja abordagem é comunicativa, que como sabemos é aquela que busca levar a realidade da língua ao aluno. As crenças e práticas dos professores e dos alunos atingiu o maior dos objetivos, talvez nem notados por eles. Enquanto o curso de inglês assegura a realidade do aluno à língua em sala de aula, o uso das mídias sociais empregou o inglês à realidade do aluno, deixando então de ser apenas uma prática, tornando-se um hábito.

\section{REFERÊNCIAS}

\section{BARBOSA, C. Apropriação das Mídias Sociais como recurso no processo} ensino-aprendizagem. Pernambuco, 2010. Anais Eletrônicos. Disponível em: $<$ https://www.ufpe.br/nehte/simposio/anais/Anais-Hipertexto-2010/Cristiane-ClebiaBarbosa.pdf $>$. Acesso em: 15 de jul. de 2015. BARCELOS, A.M.F. Metodologia de Pesquisa das Crenças sobre Aprendizagem de Línguas: Estado da Arte. Revista Brasileira de Linguística Aplicada, v.1, n .1, p. 71-92, 2001. . Cognição de professores e alunos: tendências recentes na pesquisa de crenças sobre

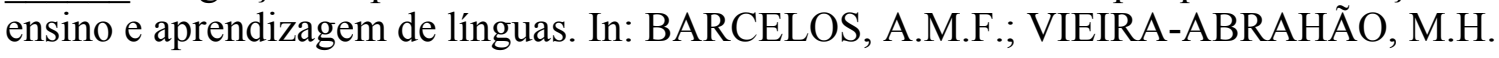


(orgs.) Crenças e Ensino de Línguas: foco no professor, no aluno e na formação de professores. Campinas, SP: Pontes, 2006. p. 15-41.

GIMENEZ, T.N. et al. A prática do ensino de inglês: desenvolvimento de competências ou legitimação das crenças? Um estudo de caso. Rev. bras. linguist. apl. vol.2 no.1 Belo Horizonte, 2002.

MARINOVIĆ, A. Comparação entre as teorias de aprendizagem e as teorias da aquisição de línguas. Lisboa, 25 ago. 2012. Disponível em:

$<$ http://www.webartigos.com/artigos/comparacao-entre-as-teorias-da-aquisicao-eaprendizagem-das-linguas/94573/\#ixzz49xWpx9cD> Acesso em: 20 de maio de 2016.

MORAN, J.M. Como utilizar a internet na educação. Revista SciELO Brasil Ci. Inf. v. 26 n. 2 Brasília Maio/Ago. 1997.

PERINA, A.A. As crenças dos professores de inglês em relação ao computador: coletando subsídios. 107f. 2003. Dissertação (Mestrado em Linguística Aplicada e Estudos da Linguagem) - Pontifícia Universidade Católica de São Paulo, São Paulo, 2003.

RODRIGUES, L.M. Língua Inglesa: conceitos, crenças e prática de ensino. Revista da Universidade Ibirapuera - Universidade Ibirapuera São Paulo, v. 4, p. 40-46, jul./dez. 2012. SILVA, K.A. Crenças e aglomerados de crenças de alunos ingressantes em Letras (Inglês). 217f. 2005. Dissertação (Mestrado em Linguística Aplicada), Instituto de Estudos da Linguagem, UNICAMP, Campinas, 2005.

Crenças sobre o ensino e aprendizagem de línguas na Linguística Aplicada: um panorama histórico dos estudos realizados no contexto brasileiro. Revista Linguagem \& Ensino, v.10, n.1, p. 235-271, jan./jun.2007.

STERN, H. Fundamental Concepts of Language Teaching. Oxford: Oxford U.P., 1983.

Submetido em 26/09/18

Aceito em 10/12/2018 